\title{
Application tannins and their sensory influence on wine Merlot
}

\author{
Sílvia Tiburski ${ }^{1, \mathrm{a}}$ and Marcos Gabbardo ${ }^{2}$ \\ ${ }^{1}$ Academic student of the Bachelor's degree in Oenology of UNIPAMPA - Dom Pedrito Campus, Brazil \\ ${ }^{2}$ Professor at the Federal University of Pampa - UNIPAMPA - Dom Pedrito Campus, Brazil
}

\section{Introduction}

The wine industry in Brazil is facing a transition phase focused on the production of quality wines with good value for money and use of alternative products in order to achieve greater diversity of public consumers both at home and abroad.

On the international scene [1] points out that the Brazilian wine industry held in 2011, the 19th place in area cultivated with grapes, 11th in grape production and the 13 th in wine production. However, this reality of Brazilian wine is still very small compared with other countries, so we emphasize more and more the importance of studies that help the expansion of wine production in the country.

The work was conducted with grapes "Merlot" from the rural área called Campanha Gaúcha in the state of Rio Grande do Sul, which is one of the regions facing the wine industry in Brazil. The cultivar Merlot has good adjustments and produces well in the region, however, the grapes, may face problems in the color of wine, due to low stability of phenolic compounds. One of the factors that can influence this stability, according [2] is the acidity, which plays an important role in sensory characteristics and physicochemical and biological stability of the wine.

On that basis we sought to investigate the use of oenological products, such as tannins, which could act chemically proposing an improvement in the final product. The use of oenological tannins is an alternative, especially when it comes to stabilizing the color, the interaction with anthocyanin pigments naturally present in wine, and how to assist in obtaining a distinct flavor profile [3].
Likewise, to be potent antioxidants, act as directly responsible for the wines aging potential, besides being in important substances from a functional point of view, considering that they are seen as beneficial to human health [4].

The study aimed to test commercial tannins evaluating its influence on sensory and physicochemical characteristics of Merlot wines.

\section{Methodology}

Classical microvinifications were performed using the yeast inoculation Saccharomyces cerevisiae, addition of nutrients, enzymes, and the use of sulfur dioxide. After separating the liquid from the skins and seeds, tannins were added to their treatment: 01-Witness, 02-Tannins Grape, 03-Tannins of Quebracho tree barrel (Schinopsis), 04-Tannins of Oak tree barrel, 05-Combination Tannin Grape + Tannin of Quebracho tree barrel (Shinopsis), 06-tannin Grape + tannin of Oak tree barrel, 07-tannin Grape associated with Polysaccharide (intermediate dose), 08-tannin Grape associated with Polysaccharide (maximum dosage), Grape 09-tannin associated with Polysaccharide + tannin of Oak tree barrel and the 10-tannin of the associated Grape Polysaccharide + tannin of Quebracho tree barrel (Shinopsis). There were physical and chemical analyses after 6 months of applying the treatments by infrared spectrometry Fourier transform (FTIR), followed by a sensory evaluation with 13 trained panelists.

Table 1. Classical physical and chemical analysis.

\begin{tabular}{|l|c|c|c|c|c|c|c|c|c|c|}
\hline \multicolumn{1}{|c|}{ Parameters } & T01 & T02 & T03 & T04 & T05 & T06 & T07 & T08 & T09 & T10 \\
\hline Alcohol & 12.86 & 12.77 & 12.32 & 12.53 & 12.49 & 12.31 & 12.58 & 12.57 & 12.46 & 12.32 \\
\hline pH & 3.55 & 3.54 & 3.54 & 3.54 & 3.55 & 3.54 & 3.54 & 3.54 & 3.54 & 3.54 \\
\hline Total acidity in H2T in pH 8.2 & 6.40 & 6.40 & 6.20 & 6.30 & 6.40 & 6.30 & 6.30 & 6.40 & 6.40 & 6.20 \\
\hline Volatile acidity & 0.6 & 0.5 & 0.5 & 0.5 & 0.5 & 0.5 & 0.5 & 0.5 & 0.5 & 0.5 \\
\hline Glycerol & 8.5 & 8.6 & 8.5 & 8.6 & 8.8 & 8.5 & 8.5 & 8.6 & 8.5 & 8.7 \\
\hline Density & 0.993 & 0.993 & 0.993 & 0.993 & 0.993 & 0.993 & 0.993 & 0.993 & 0.993 & 0.993 \\
\hline
\end{tabular}

The averages are not statistically different from each other. It was applied the Tukey test at $5 \%$ probability.

${ }^{a}$ Corresponding author: silviatiburski@gmail.com

This is an Open Access article distributed under the terms of the Creative Commons Attribution License 4.0, which permits unrestricted use, distribution, and reproduction in any medium, provided the original work is properly cited. 


\section{Results and discussion}

The classic variables $(\mathrm{pH}$, alcohol, total acidity, volatile acidity, glycerol and density) showed no significant differences when submitted to the Tukey test at 5\% probability, as can be seen in Table 1 .

In relation to the wine color, expressed in Table 2 , the indexes 420, 520 and 620 show significant differences, but 420 does not present much interest in this study because it is the representation of yellow color. With respect to the index 520, two treatment grape tannins was the most representative, followed by 5 grape tannins + Quebracho tree barrel tannin, this result was obtained probably due to affinity of tannins added with chemicals of the wine. While treatment 3 quebracho tree barrel tannin had the lowest result, showing itself interesting to use. However, these values were very important, since they are higher than those found by [5], where the same content with the addition of tannins obtained his best result in 0.4593 Cabernet Sauvignon wine, unlike this study where the lowest value was 0.5336 .

For the index 620, again the second treatment was the best and this result proves to be very positive in view of this index is the color of the wines aging potential. Treatment 5 also remained and the lowest result was for the witness, proving that the use of tannins influence positively the quality and potential of custody of wines.

The color intensity was higher in the wines that were added grape tannin, and the grape-based treatments with polysaccharide were also good and again the quebracho tannin printed the lowest result. Good results found in Treatment 2 also occurred in Portugal, in a study evaluating application tannins and use of pre-fermentation cold maceration in red, where the modality that received grape tannins showed a higher value for the color intensity (Corte-Real, 2009).

The color tone, the witness had the lowest result and grape tannin to polysaccharide + quebracho tannin obtained differentiation of other treatments followed by the grape tannin to polysaccharide + oak tannin.

For the total polyphenol index treating 05 , grape tannin with Quebracho was the most representative, as shown in Table 3.

Table 2. Chromatic analysis.

\begin{tabular}{|cccc|}
\hline Treatments & A 420 & A 520 & A620 \\
\hline T01 & $0.52667 \mathbf{d}$ & $0.81633 \mathbf{b c}$ & $0.14733 \mathbf{e}$ \\
\hline T02 & $0.57533 \mathbf{a}$ & $0.86233 \mathbf{a}$ & $0.16433 \mathbf{a}$ \\
\hline T03 & $0.53367 \mathbf{d}$ & $0.78233 \mathbf{c d}$ & $0.14800 \mathbf{d e}$ \\
\hline T04 & $0.5456 \mathbf{b c d}$ & $0.81400 \mathbf{c d}$ & $0.15600 \mathbf{a b c d}$ \\
\hline T05 & $0.56533 \mathbf{a b c}$ & $0.83300 \mathbf{a b}$ & $0.16067 \mathbf{a b}$ \\
\hline T06 & $0.54167 \mathbf{b c d}$ & $0.78433 \mathbf{c d}$ & $0.1496 \mathbf{c d e}$ \\
\hline T07 & $0.53867 \mathbf{c d}$ & $0.77767 \mathbf{d}$ & $0.14967 \mathbf{c d e}$ \\
\hline T08 & $0.56767 \mathbf{a b}$ & $0.8100 \mathbf{b c d}$ & $0.15700 \mathbf{a b c}$ \\
\hline T09 & $0.56633 \mathbf{a b}$ & $0.81467 \mathbf{b c d}$ & $0.15867 \mathbf{a b}$ \\
\hline T10 & $0.56633 \mathbf{a b}$ & $0.80367 \mathbf{b c d}$ & $0.15400 \mathbf{b c d e}$ \\
\hline
\end{tabular}

The averages are not statistically different from each other. It was applied the Tukey test at $5 \%$ probability.
Table 3. Intensity of color and hue of Folin-Ciocalteu Index.

\begin{tabular}{|c|c|c|c|}
\hline Treatments & Intensity & Tonality & $\begin{array}{c}\text { Folin-Ciocalteu } \\
\text { index }\end{array}$ \\
\hline T01 & 1.49033 bcde & $0.64518 \mathbf{d}$ & $39.20000 \mathbf{c}$ \\
\hline T02 & $1.60200 \mathbf{a}$ & $0.66720 \mathbf{c}$ & $41.83333 \mathbf{b}$ \\
\hline T03 & $1.46400 \mathbf{e}$ & $0.68215 \mathbf{b c}$ & $41.06667 \mathbf{b c}$ \\
\hline T04 & $1.51567 \mathbf{b c d e}$ & $0.67036 \mathbf{c}$ & $41.23333 \mathbf{b}$ \\
\hline T05 & $1.55900 \mathbf{a b}$ & $0.67869 \mathbf{b c}$ & $43.73333 \mathbf{a}$ \\
\hline T06 & $1.47567 \mathbf{c d e}$ & $0.69061 \mathbf{a b}$ & $41.16667 \mathbf{b}$ \\
\hline T07 & $1.46600 \mathbf{d e}$ & $0.69261 \mathbf{a b}$ & $40.96667 \mathbf{b c}$ \\
\hline T08 & $1.53467 \mathbf{a b c d}$ & $0.70089 \mathbf{a}$ & $42.30000 \mathbf{a b}$ \\
\hline T09 & $1.53967 \mathbf{a b c}$ & $0.69512 \mathbf{a b}$ & $41.56667 \mathbf{b}$ \\
\hline T10 & $1.52400 \mathbf{b c d e}$ & $0.70480 \mathbf{a}$ & $42.40000 \mathbf{a b}$ \\
\hline
\end{tabular}

The averages are not statistically different from each other. It was applied the Tukey test at $5 \%$ probability.

The gelatin index, which represents the astringent tannins presented differences to the treatment 08 , the lowest value found and tannins mix of treatments $6,7,9$ and 10 showed the highest values with no significant difference between them, allowing concluding that wines such treatments require a larger guard time for the complexation of compounds. For Zamora [6], the gelatin content must be between young wines between 25 and $80 \%$. Values above $60 \%$ indicated that it is a very astringent loaded wine tannins. Values below $35 \%$ indicated that wine needs corps. Finally, values between 40 and $60 \%$ are considered the most convenient. But the ethanol content deals with noble tannins and showed no statistical difference between treatments.

Finally, the sensory of the wines presented interesting trends, but no statistical differences except in two parameters of taste evaluation.

Aroma, was highlighted the trend of higher quality in the treatments with tannins, for the variables initial attack, intensity, distinctness, quality, red fruit and spices

Table 4. Gelatin and ethanol indexes.

\begin{tabular}{|c|c|c|}
\hline Treatments & Gelatin & Ethanol \\
\hline T01 & $61.15333 \mathbf{a b}$ & $9.36667 \mathbf{a}$ \\
\hline T02 & $62.85333 \mathbf{a b}$ & $8.90667 \mathbf{a}$ \\
\hline T03 & $62.30667 \mathbf{a b}$ & $8.68000 \mathbf{a}$ \\
\hline T04 & $64.01000 \mathbf{a b}$ & $8.16333 \mathbf{a}$ \\
\hline T05 & $62.02333 \mathbf{a b}$ & $8.51333 \mathbf{a}$ \\
\hline T06 & $70.62334 \mathbf{a}$ & $8.63333 \mathbf{a}$ \\
\hline T07 & $70.16333 \mathbf{a}$ & $8.26000 \mathbf{a}$ \\
\hline T08 & $56.25667 \mathbf{b}$ & $8.24333 \mathbf{a}$ \\
\hline T09 & $71.26334 \mathbf{a}$ & $9.04667 \mathbf{a}$ \\
\hline T10 & $72.94666 \mathbf{a}$ & $8.95333 \mathbf{a}$ \\
\hline
\end{tabular}

The averages are not statistically different from each other. It was applied the Tukey test at $5 \%$ probability. 
Table 5. Aromatic profile of wines.

\begin{tabular}{|l|c|c|c|c|c|c|c|c|c|c|}
\hline \multicolumn{1}{|c|}{ Olfactory } & T01 & T02 & T03 & T04 & T05 & T06 & T07 & T08 & T09 & T10 \\
\hline Initial attack & $6.84 \mathbf{a}$ & $6.48 \mathbf{a}$ & $6.61 \mathbf{a}$ & $6.71 \mathbf{a}$ & $6.79 \mathbf{a}$ & $6.64 \mathbf{a}$ & $6.48 \mathbf{a}$ & $6.74 \mathbf{a}$ & $6.89 \mathbf{a}$ & $6.89 \mathbf{a}$ \\
\hline Intensity & $6.25 \mathbf{a}$ & $6.35 \mathbf{a}$ & $6.35 \mathbf{a}$ & $6.46 \mathbf{a}$ & $6.56 \mathbf{a}$ & $6.64 \mathbf{a}$ & $6.46 \mathbf{a}$ & $6.43 \mathbf{a}$ & $6.69 \mathbf{a}$ & $6.82 \mathbf{a}$ \\
\hline Distinctness & $6.30 \mathbf{a}$ & $6.17 \mathbf{a}$ & $6.25 \mathbf{a}$ & $6.07 \mathbf{a}$ & $6.41 \mathbf{a}$ & $6.23 \mathbf{a}$ & $5.97 \mathbf{a}$ & $6.40 \mathbf{a}$ & $6.58 \mathbf{a}$ & $6.89 \mathbf{a}$ \\
\hline Quality & $6.97 \mathbf{a}$ & $6.97 \mathbf{a}$ & $7.07 \mathbf{a}$ & $6.99 \mathbf{a}$ & $7.10 \mathbf{a}$ & $6.99 \mathbf{a}$ & $6.84 \mathbf{a}$ & $6.87 \mathbf{a}$ & $7.12 \mathbf{a}$ & $6.97 \mathbf{a}$ \\
\hline Red fruits & $5.07 \mathbf{a}$ & $5.43 \mathbf{a}$ & $5.43 \mathbf{a}$ & $5.69 \mathbf{a}$ & $5.35 \mathbf{a}$ & $5.07 \mathbf{a}$ & $4.94 \mathbf{a}$ & $5.07 \mathbf{a}$ & $5.28 \mathbf{a}$ & $5.51 \mathbf{a}$ \\
\hline Vegetable/herb & $1.94 \mathbf{a}$ & $2.07 \mathbf{a}$ & $2.17 \mathbf{a}$ & $1.97 \mathbf{a}$ & $2.07 \mathbf{a}$ & $2.41 \mathbf{a}$ & $2.05 \mathbf{a}$ & $2.07 \mathbf{a}$ & $2.28 \mathbf{a}$ & $2.43 \mathbf{a}$ \\
\hline Spices/toasted & $3.66 \mathbf{a}$ & $3.56 \mathbf{a}$ & $2.99 \mathbf{a}$ & $3.25 \mathbf{a}$ & $3.74 \mathbf{a}$ & $2.94 \mathbf{a}$ & $3.33 \mathbf{a}$ & $3.69 \mathbf{a}$ & $4.12 \mathbf{a}$ & $3.92 \mathbf{a}$ \\
\hline
\end{tabular}

The averages are not statistically different from each other. It was applied the Tukey test at $5 \%$ probability.

descriptors/toasted treatments 09 and 10 showed the best results in scoring range 6.8 to 7 while the witness remained 6.2 as can be seen in Table 5. Cheynier et al. [7] pointed out the possibility of polyphenolics contribute to aromas such as vanillin, these compounds can then contribute to aroma intensity and quality.

Regarding the gustatory analysis (Table 6) treatments 9 and 10 were the best for balance and volume in the mouth, followed by the witness with the lowest value, surely the combination of tannin with polysaccharide was important in this regard and the quebracho tannin helped positively too. The mouthfeel was also satisfactory in the treatment of grape tannin, which [5] obtained good results for persistence, corps and structure.

Persistence was higher in the witness, perhaps show a more varietal characteristic. Regarding the sense of astringency treatments 9 and 6 excelled, probably by the presence of ellagic tannins. The other features are understood sweetness, acidity, bitterness, tannins, where we got statistical difference.
Regarding round tannins, also known as polymerized, grape tannins treatments with polysaccharide associated with quebracho and oak tannins stood out, confirming what has been expected of them, presenting statistical difference from the others, it is clear also that again the control treatment had the lowest values.

The ripe fruit has anthocyanins with certain condensation with each other and tannins. The tannins in turn, are astringent and reactive with saliva when the molecular weight reaches 500. Initially, the monomers are rough. With the polymer association with anthocyanins, you lose this activity. Harmony polymerization anthocyanin-tannins with oxygen intervention generates stable color and smoothness. The lack of oxygen prevents the prolonging herbaceous flavor and missing red [8].

In this overall assessment, all the wines of the 2014 harvest that went through sensory analysis had assigned notes, with values ranging from 80 to 87 points, proving the quality of grapes and wine, as they were not needed

Table 6. Flavor profile of wines.

\begin{tabular}{|l|c|c|c|c|c|c|c|c|c|c|}
\hline \multicolumn{1}{|c|}{ Gustatory } & T01 & T02 & T03 & T04 & T05 & T06 & T07 & T08 & T09 & T10 \\
\hline Mouth volume & $6.282 \mathbf{a}$ & $6.512 \mathbf{a}$ & $6.487 \mathbf{a}$ & $6.564 \mathbf{a}$ & $6.512 \mathbf{a}$ & $6.487 \mathbf{a}$ & $6.564 \mathbf{a}$ & $6.564 \mathbf{a}$ & $6.717 \mathbf{a}$ & $6.923 \mathbf{a}$ \\
\hline Balance & $6.358 \mathbf{a}$ & $6.153 \mathbf{a}$ & $6.358 \mathbf{a}$ & $6.230 \mathbf{a}$ & $6.230 \mathbf{a}$ & $6.461 \mathbf{a}$ & $6.230 \mathbf{a}$ & $6.256 \mathbf{a}$ & $6.512 \mathbf{a}$ & $6.923 \mathbf{a}$ \\
\hline Persistence & $6.256 \mathbf{a}$ & $5.999 \mathbf{a}$ & $5.769 \mathbf{a}$ & $5.974 \mathbf{a}$ & $6.051 \mathbf{a}$ & $5.948 \mathbf{a}$ & $5.923 \mathbf{a}$ & $5.948 \mathbf{a}$ & $5.666 \mathbf{a}$ & $5.974 \mathbf{a}$ \\
\hline Astringency & $4.871 \mathbf{a}$ & $4.999 \mathbf{a}$ & $5.307 \mathbf{a}$ & $5.205 \mathbf{a}$ & $5.487 \mathbf{a}$ & $5.640 \mathbf{a}$ & $5.307 \mathbf{a}$ & $5.435 \mathbf{a}$ & $5.769 \mathbf{a}$ & $5.025 \mathbf{a}$ \\
\hline Sweetness & $2.435 \mathbf{a}$ & $2.153 \mathbf{a}$ & $2.282 \mathbf{a}$ & $2.435 \mathbf{a}$ & $2.487 \mathbf{a}$ & $2.384 \mathbf{a}$ & $2.205 \mathbf{a}$ & $2.179 \mathbf{a}$ & $2.461 \mathbf{a}$ & $2.256 \mathbf{a}$ \\
\hline Acidity & $5.205 \mathbf{a}$ & $5.153 \mathbf{a}$ & $5.076 \mathbf{a}$ & $5.128 \mathbf{a}$ & $5.051 \mathbf{a}$ & $5.153 \mathbf{a}$ & $5.102 \mathbf{a}$ & $5.153 \mathbf{a}$ & $5.205 \mathbf{a}$ & $5.615 \mathbf{a}$ \\
\hline Bitterness & $0.666 \mathbf{a}$ & $0.871 \mathbf{a}$ & $0.666 \mathbf{a}$ & $0.743 \mathbf{a}$ & $0.897 \mathbf{a}$ & $0.948 \mathbf{a}$ & $1.082 \mathbf{a}$ & $1.025 \mathbf{a}$ & $0.794 \mathbf{a}$ & $0.743 \mathbf{a}$ \\
\hline Round Tannins & $5.230 \mathbf{b}$ & $4.923 \mathbf{b}$ & $5.282 \mathbf{a b}$ & $5.307 \mathbf{a b}$ & $4.999 \mathbf{b}$ & $5.153 \mathbf{b}$ & $5.435 \mathbf{a b}$ & $5.384 \mathbf{a b}$ & $5.794 \mathbf{a b}$ & $6.333 \mathbf{a}$ \\
\hline
\end{tabular}

The averages are not statistically different from each other. It was applied the Tukey test at $5 \%$ probability. 
any corrections, the Similarly the application of tannin was of particular interest to increase the quality of wines.

\section{Conclusion}

The grape tannin and grape tannin mix with quebracho tannin proved to be important tools in chromatic composition and total polyphenols. The quebracho tannin showed no positive results, since the smaller values for the color index, intensity and hue in this treatment were followed grape tannins treatment + oak tannin. Already grape tannins associated with polysaccharides in combination with oak tannin and quebracho acted positively on the sensory characteristics of the wines, especially emphasizing the part of tannins, they also had the best scores by the assessors.

To the Company Amazon Group, for their support and availability of inputs for the preparation of this work.

\section{References}

[1] MELLO, R. M. L; Atuação do Brasil no Mercado Vitivinícola Mundial: Panorama 2012. Comunicado Técnico 138 Bento Gonçalves, 2013
[2] RIZZON, A. L.; MIELE, A.; Acidez na vinificação em tinto das uvas Isabel, Cabernet Sauvignon $e$ Cabernet Franc. Ciência Rural, Santa Maria 2002

[3] GIOVANNINI, E.; MANFROI,V.; Viticultura $e$ enologia: elaboração de grandes vinhos nos terroirs brasileiros. Bento Gonçalves, IFRS, 2009.

[4] SOUZA F, J.M.; MANFROI, V.Vinho $e$ saúde: vinho como alimento natural. Bento Gonçalves: IBRAVIN, 2005.

[5] MANFROI, Vitor:;Taninos enológicos $e$ goma arábica na composição $e$ qualidade sensorial do vinho Cabernet Sauvignon. Tese de doutorado, Pelotas 2007.

[6] ZAMORA, Fernando. Elaboración y crianza Del vino tinto: Aspectos científicos $y$ prácticos. $1^{\circ} \mathrm{Ed}$. Madri (Espanha) Mundi-Prensa 2003

[7] CHEYNIER, Véronique; DUEÑAS-PATON, Montserrat; SALAS, Erika; MAURY, Chantal; SOUQUET, Jean - Marc. ; SARNI - MANCHADO, Pascale ; FULCRAND, Héléne. Structure and properties of wine pigments and tannins. American Journal of Enology and Viticulture, Davis, 2006.

[8] MILANI, Carina Ariotti. A evolução dos polifenóis do vinho tinto Merlot durante a maturação em barricas de carvalho francês. Trabalho de conclusão de curso, Bento Gonçalves - RS 2011. 